\title{
Correction to: Inhibitory Effects of Bisphenol-A on Neural Stem Cells Proliferation and Differentiation in the Rat Brain Are Dependent on Wnt/ß-Catenin Pathway
}

\author{
Shashi Kant Tiwari ${ }^{1,2} \cdot$ Swati Agarwal ${ }^{1,2} \cdot$ Brashket Seth $^{1,2} \cdot$ Anuradha Yadav $^{1,2} \cdot$ Ratan Singh Ray $^{3} \cdot$ \\ Vijay Nath Mishra ${ }^{4} \cdot$ Rajnish Kumar Chaturvedi ${ }^{1,2}$
}

Published online: 4 July 2019

(C) Springer Science+Business Media, LLC, part of Springer Nature 2019

\section{Correction to: Mol Neurobiol (2015) 52:1735-1757 \\ https://doi.org/10.1007/s12035-014-8940-1}

The original version of this article unfortunately contained a mistake.

The authors observed inadvertent error in Figure $3 \mathrm{~A}$ and $6 \mathrm{C}$ wish to correct it. The corrected representative images are incorporated below. This correction in no way changes the text of the article, conclusion and figure legend. The authors regret for this error and would like to apologize for any inconvenience caused to the readers.

The online version of the original article can be found at https://doi.org/ 10.1007/s12035-014-8940-1

Rajnish Kumar Chaturvedi

rajnish@iitr.res.in

1 Developmental Toxicology Division, Systems Toxicology Group, CSIR-Indian Institute of Toxicology Research (CSIR-IITR), 80-MG Marg, Lucknow, Uttar Pradesh, India

2 Academy of Scientific and Innovative Research (AcSIR), New Delhi, India

3 Photobiology Division, CSIR-Indian Institute of Toxicology Research (CSIR-IITR), 80-MG Marg, Lucknow, Uttar Pradesh, India

4 Department of Neurology, Institute of Medical Sciences, Banaras Hindu University, Varanasi, Uttar Pradesh, India 


\section{Corrected Figure}

a

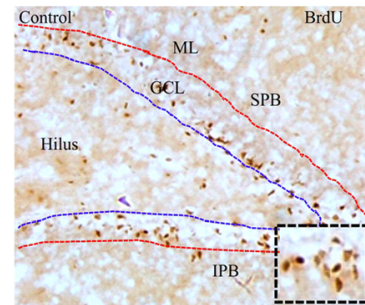

BPA $40 \mu \mathrm{g}$

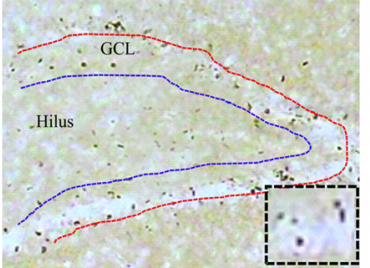

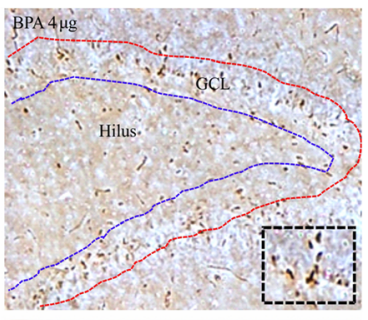

$\overline{\mathrm{BPA}} 400 \mu \mathrm{g}$

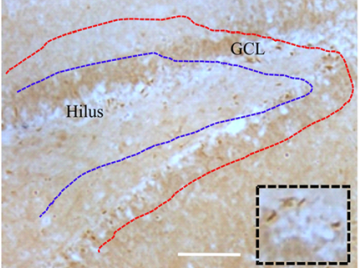

c
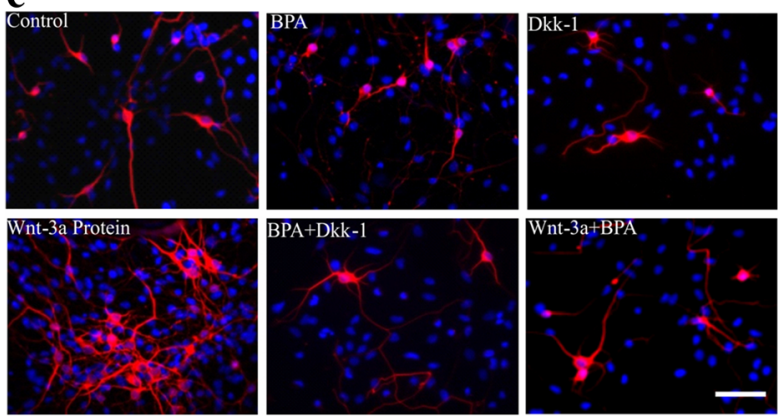

BPA+Dkk-1

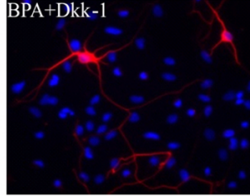

Wnt-3a+BPA

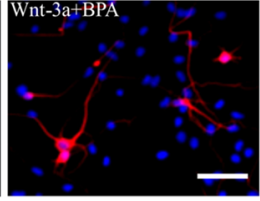

Publisher's Note Springer Nature remains neutral with regard to jurisdictional claims in published maps and institutional affiliations. 